\title{
Stressors and vulnerability during upper secondary school: subjective experiences of classroom climate and coping beliefs as predicting factors of school stress in Norway
}

\author{
Jan Arvid Haugan $^{1}$ (D) Per Frostad ${ }^{1} \cdot$ Per-Egil Mjaavatn ${ }^{1}$
}

Received: 16 February 2021 / Accepted: 18 August 2021 / Published online: 30 August 2021

(c) The Author(s) 2021

\begin{abstract}
The present longitudinal study was designed to scrutinize how adolescents perceive their life in upper secondary schools in general, and how central aspects of their perceived classroom climate predicted their coping beliefs and experience of school stress in particular. The participants were 1215 students in upper secondary schools (grades 2 and 3) from one county in Norway. The data were analysed by means of structural equation modelling, and the findings reveal gender differences that need further investigation in future research. Our study indicates that a performance-oriented goal structure and social support from peers and teachers seem to be a potential risk factor and/or protective factor when it comes to adolescents' development of coping beliefs and experiences of school stress, especially among girls.
\end{abstract}

Keywords Performance-oriented goal structure $\cdot$ Social support $\cdot$ Coping beliefs . Stress

\section{Introduction}

Increasing academic demands and expectations are facilitating students' learning and development as they move through the educational system. At the same time, these evolving challenges and responsibilities appear to be closely linked to perceptions of stress among adolescents (Klinger et al., 2015; Löfstedt et al., 2019). The literature often separates between objective stress stimuli (stressors) and the

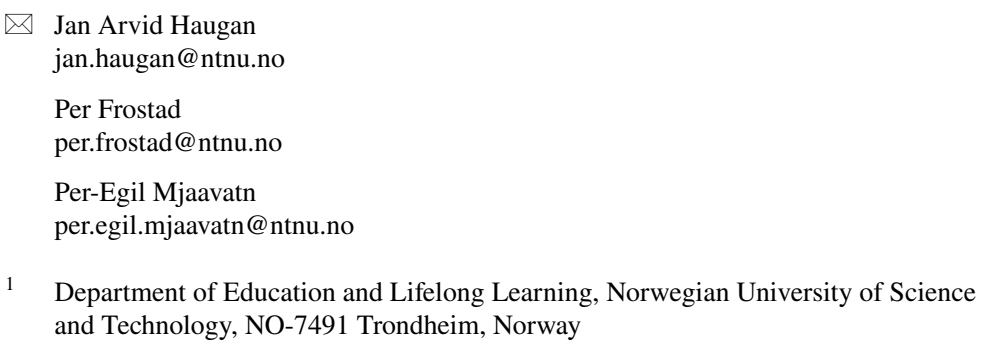


individual's subjective stress response (e.g. Byrne et al., 2007; Montgomery, 2012). Stressors include the expectations and challenges that adolescents face in their everyday life at school. In his seminal work, Selye (1956) distinguished between positive (eustress) and negative (distress) stressors. Eustress is associated with positive emotions and can be understood as manageable challenges that provide the basis for learning and development. Distress, however, leads to psychological or emotional activation that will negatively affect students' abilities to learn and perform tasks (Tyng et al., 2017; Vogel \& Schwabe, 2016). In this article, we refer to distress when we discuss the stress concept.

Several studies have shown that high levels of stress have a strong correlation with mental health problems such as depression, panic attacks, and anxiety (Eisenberg et al., 2011; Morris et al., 2010). This association seems to be moderated through stress management beliefs (Sawatzky et al., 2012; Varghese et al., 2015). In addition, other research indicates that stress negatively predicts academic performance, especially grades, in both lower secondary (Bücker et al., 2018; Goldstein et al., 2015), and upper secondary school (Pascoe et al., 2020; Schraml et al., 2012). In sum, these findings suggest a reciprocal relationship between high levels of stress and mental health, and low levels of academic performance.

The prevalence of school stress is prominent in the Nordic countries (Lillejord et al., 2017; Löfstedt et al., 2019; Ringdal et al., 2020). This mirror findings from a cross-national survey involving 72 countries and consisting of 540000 student respondents aged 15-16, conducted by the Organization for Economic Co-operation and Development (OECD, 2017), where 66\% of the students reported feeling stressed about poor grades, and $37 \%$ reported feeling tense at school. Furthermore, school stress seems to be higher among girls compared with boys (Dalen, 2014; Klinger et al., 2015). These gender differences are usually explained from two main perspectives. The first is based on the notion that girls are exposed to stronger or more stressors across different contexts in their life ecology (Hankin et al., 2007; Högberg et al., 2020). The second is that girls may be more vulnerable towards stressors at school as they have higher academic ambitions, and seem to be more responsive to the demands and the expectations of others (Bakken et al., 2018; Giota \& Gustafsson, 2016).

After the first PISA survey in Norway in 2001, there has been growing focus on testing and comparison of results between schools. Previous research has found that students experience the school as increasingly more performance oriented as they grow older (Patrick et al., 2011; Skaalvik \& Skaalvik, 2013). In addition, a connection is found between the increase in stress during adolescence and the growing focus on testing and performance in schools (Eriksen et al., 2017; Lillejord et al., 2017). On the other hand, it has been reported that some factors protect students against the development of stress in schools. These include, optimistic coping beliefs (Groth et al., 2019; Thapar et al., 2012), and supportive interpersonal relationships with peers, (Pargas et al., 2010; Silk et al., 2007), and teachers (Jennings \& Greenberg, 2009; Krane et al., 2016).

The theoretical framework in this article is based on Lazarus and Folkman's (1984) transactional model of stress and coping. This model describes the cognitive appraisal of stressors in three phases. The first phase (primary appraisal) deals with 
the individual's assessment of the threat level, based on both the objective extent of stressors and the person's subjective experience of them. From this perspective, interpretations of whether something is actually perceived as a stressor are influenced by subjective values and goals connected to how important it is for the individual to manage the situation. When the mastery of a stressor is highly relevant and consistent with one's needs and well-being, the situation elicits a more intense emotional response (Oltenau et al., 2019; Smith \& Kirby, 2009). The second phase (secondary appraisal) involves an evaluation of available social support and personal coping abilities. When coping beliefs are low, even small stressors can trigger stress. On the other hand, individuals who have optimistic coping beliefs will be more robust when it comes to coping with the stressors they are exposed to (Groth et al., 2019; Johnson et al., 2017). The last phase deals with the individual's stress response and coping strategies. If the increasing pressure at school becomes too high, students may perceive that the prevailing demands and expectations exceed their available personal and social resources (Salmela-Aro, 2017; Walburg, 2014). Research indicates that such stress responses often will be accompanied by pessimistic beliefs concerning a person's ability to cope with issues such as schoolwork (Groth et al., 2019; Liu et al., 2015). In sum, in addition to the extent of objective demands and expectations over time, the subjective experience is a key concept when exploring the development of stress. It is not solely the pressure from stressors, but also how the situation is appraised, and perceptions of available personal and social resources, that determine experiences of stress (Lazarus, 1966; Lazarus \& Folkman, 1984).

In the present study we will use this theoretical framework as an analytical tool to distinguish between Norwegian students' appraisal of the amount of pressure they are exposed to, their perceptions of personal and social resources, and experience of school stress during their last two years of Upper Secondary School. Therefore, we will not investigate the students' stress response and coping strategies, but demarcate our exploration to how the first two phases in Lazarus and Folkman's (1984) transactional model lead to experiences of stress. In the following, we will review research on the associations between adolescents' perceptions of classroom climate, coping beliefs and school stress. This literature review ends with a formulation of a primary research question with five related hypotheses.

\subsection{Classroom climate, coping beliefs and school stress}

The classroom climate has been defined in various ways. Nevertheless, there is a consensus in conceptualizing the classroom climate as a multidimensional concept (Pianta \& Hamre, 2009; Wang \& Degol, 2016). This includes "the organisation and structure of the classroom environment; pedagogical, disciplinary, and curriculum practices; and interpersonal relationships among students, peers and teachers" (Wang et al., 2020, p.2). The classroom climate has been found to be strongly associated with coping beliefs (Mehta et al., 2018; Rolland, 2012), and school stress (Byrne et al., 2007; Högberg et al., 2020). Five literature reviews have found evidence that aspects of the classroom climate are related to several affective, 
behavioural, academic, health-related, and interpersonal outcomes among adolescents (Aldrige \& McChesney, 2018; Thapar et al., 2012; Cohen et al., 2009; Thapa et al., 2013; Wang \& Degol, 2016). However, examining the previous research in these reviews indicates a further need to explore of how key aspects of the school climate affect specific student outcomes such as coping beliefs or school stress. In addition, much of the school climate research lacks explicit theoretical underpinnings such as Lazarus and Folkman's (1984) transactional model of stress and coping that is used in the present study. Based on this, we have demarcated our study to the exploration of the classroom climate to the perceptions of the performanceoriented goal structure in the students' classrooms and the social support from peers and teachers, and how these distinct elements affect students' coping beliefs and experiences of school stress.

\subsubsection{Performance-oriented goal structure}

The construct of goal structure arose out of achievement goal theory (Ames \& Archer, 1988; Nicholls, 1984). It is conceptualized as competence-relevant environmental emphasis made prominent through "messages in the learning environment (e.g., the classroom or school) that make certain goals salient" (Urdan \& Schoenfelder, 2006, p. 400). The goal structure is communicated in various ways and from different sources. We can separate the various levels such as the societal level, the school level, the class level and the individual level. At the societal level the goal structure signals can be sent through the public debate, methods for school assessments, and governmental plans and regulations. In addition, each school and each teacher can consciously and unconsciously signal what is important in school to each of the students. This has implications for the individual level. The goal structure is perceived subjectively and individually for each student (Hulleman et al., 2010; Tian et al., 2017). This implies that two students in the same society, school and class may perceive different goal structures.

In a performance-oriented goal structure, the students perceive learning predominantly as a means to achieve recognition of worth and extrinsic rewards. Performance in standardized tests and the like is emphasized and success is indicated by social comparison with peers in class, other classes or normative standards. Thus, the results are interpreted in terms of students' relative performance (Ames, 1992; Meece et al., 2006). Girls seem to report higher levels of a performance-oriented goal structure and school pressure compared with boys (Klinger et al., 2015; Löfstedt et al., 2020), and research indicates that this has several negative outcomes. These include increased occurrence of cheating (Anderman et al., 2009), academic self-handicapping (Urdan, 2004), procrastination (Wolters, 2004), lower levels of positive relations towards both peers and teachers (Lerang et al., 2019; Polychroni et al., 2012), decreased coping beliefs when facing stressors (Dull et al., 2015; Huang, 2016), and an increased experience of school stress (Randall et al., 2019; Wang et al., 2020). These findings from previous studies lead us to expect that a perceived performance-oriented goal structure has a negative association with coping beliefs and a positive association with experiences of school stress, especially among girls. 


\subsubsection{Social support}

Social support is another classroom climate variable that seems to affect students' experience of coping beliefs and school stress. This relationship is implicit in the following definition that views social support as: “(...) an individual's perception of general support or specific supportive behaviors (available or enacted upon) from people in their social network, which enhances their functioning and/or may buffer them from adverse outcomes" (Malecki \& Demaray, 2002, p. 2). The most important sources for support in adolescents' social networks are family, peers and teachers (Danielsen et al., 2009; Tian et al., 2016). Having positive social relationships is recognized as a basic psychological need and seems critical for engagement and optimistic coping beliefs at school (Deci \& Ryan, 2000; Poots \& Cassidy, 2020).

The teacher-student relationship is often mentioned when teachers and students are asked about the key factors in a good learning environment and what matters most for the students' academic development (Patrick et al., 2011) and well-being at school (Zullig et al., 2011). The students' sense of teacher support seems to affect the development of enhanced motivation and higher academic performance (Davis, 2006), as well as more positive relationships with peers (Wentzel et al., 2010). In addition, such students also report less emotional distress (Lei et al., 2018; Suldo et al., 2009), and higher levels of perceived ability and mastery expectations (Sowislo \& Orth, 2013; Yeoh et al., 2017), compared to students who experience lower levels of teacher support. In contrast, a deteriorating teacher-student relationship is associated with aggression (Henry et al., 2011), dropout (Fortin et al., 2013), poorer academic performance (Givens Rolland, 2012), higher levels of experienced stress (Gallagher \& Vella-Brodrick, 2008; Kong et al., 2013), and similar negative student outcomes (Rudasill et al., 2010). Other research studies have found that peer support is even more important than teacher support for adolescents' coping beliefs and experience of school stress (Arslan, 2009; Turner, 1999). Findings indicate that students with positive peer relationships are more behaviourally and emotionally engaged in school (Garcia-Reid, 2007; Long \& Sweeting, 2020). This contrasts with those who experience peer rejection (French \& Conrad, 2001). Research has also found positive effects of close friendships and that positive interactions with friends foster interpersonal and intrapersonal protective buffers such as increased coping beliefs (Raboteg-Saric \& Sakic, 2014), and reduced experiences of school stress (Moses \& Villodas, 2017).

Research on gender differences report how girls and boys perceive support and the effect it has on coping beliefs and school stress (Cheng \& Chan, 2004; Rueger et al., 2008). Girls seem to experience more support from peers than from teachers, while boys perceive less support from both teachers and peers compared with girls. In addition, some researchers claim that social support might be more important for girls as interpersonal stressors are stronger predictors of negative psychological outcomes among girls compared with boys (Hankin et al., 2007; Rose \& Rudolph, 2006). Based on this previous research, we expected that both peer and teacher support were positively related to coping beliefs, and negatively related to experiences of school stress, especially among girls. 


\subsection{The present study}

The present study was designed to explore how students perceive life in school in general, and how central aspects of the school ecology predict their coping beliefs and experiences of school stress in particular. Based on the literature review, the following research question was formulated: "Are upper secondary school students' perceptions of coping beliefs and school stress related to gender, the performanceoriented goal structure in the classroom and their perceptions of social support from teachers and peers?" Based on this research question and our findings from the literature review, five hypotheses were formulated, and a theoretical path model was specified:

- H1: Girls perceive lower levels of coping beliefs and higher levels of school stress, compared with boys (Dalen, 2014; Klinger et al., 2015).

- H2: A performance-oriented goal structure will predict coping beliefs negatively and school stress positively (Huang, 2016; Wang et al., 2020).

- H3: Peer support will predict coping beliefs positively and school stress negatively (Moses \& Villodas, 2017; Raboteg-Saric \& Sakic, 2014).

- H4: Teacher support will predict coping beliefs positively and school stress negatively (Kong et al., 2013; Sowislo \& Orth, 2013)

- H5: Coping beliefs will predict school stress negatively (Groth et al., 2019; Johnson et al., 2017)

\section{Method}

\subsection{Participants and procedure}

This study was part of a larger data collection and analysis of students' perceptions of their life in school. The compulsory elementary school in Norway consists of 10 years of education-seven in primary school and three in lower secondary school. Upper secondary school is not compulsory, but the publicly funded education provides this as a statutory right to adolescents aged up to 21 . Almost $98 \%$ of the students who complete elementary school in 10th grade immediately enrol in upper secondary education (Statistics Norway, 2018). The sample comprises 1215 students (63\% response rate), 688 girls and 527 boys, in upper secondary school (grades 2 and 3, aged approximately 17-18), from both rural and urban areas in thirteen schools in one county in Norway. We used longitudinal data to record change over time for an individual, developmental differences between groups (e.g. gender), and to examine causal relationships amongst theoretically relevant variables over time (Card \& Little, 2007; Shek \& Catalina, 2016). The data can be described as a convenience sample (McQueen \& Knussen, 2006), and were collected in the spring of 2017 and 2018.

The informants were made familiar with the study's voluntary participation and that we appraised their consent as they handed in a completed questionnaire. The 
data were collected on paper-based questionnaires and administrated by members of the research team. The Norwegian Centre for Research Data approved the survey.

\subsection{Instruments}

All scales were measured with items answered on a six-point Likert scale from $1=$ very untrue to $6=$ very true, and the reliability was measured by Cronbach's alpha.

\subsubsection{Performance-oriented goal structure}

Students' perception of the classroom performance-oriented goal structure in upper secondary school grade 2 was evaluated with four items based on the Patterns of Adaptive Learning Scales (PALS) (Midgley et al., 2000). Examples of statements: "The most important thing in our class is to get good grades", "The most important thing in our class is to perform well in school". Cronbach's alpha for the scale was $0.87 / 0.86$ for girls/boys, respectively.

\subsubsection{Social support}

Social Support from Peers in upper secondary school grade 2 was measured with four items from The Child and Adolescent Social Support Scale (CASSS) (Malecki \& Demary, 2002). Examples: "My classmates are nice to me" and "My classmates treat me with respect". Cronbach's alpha for the scale was 0.83 for both girls and boys.

The prevailing research literature discusses whether Teacher support should be described as a multidimensional phenomenon or by a single underlying quality (Downer et al., 2015). For instance, Pianta et al. (2010) suggest dividing the concept in three: emotional support, academic support and classroom organization. In line with this, we constructed two scales; one for emotional support and one for academic support from the teacher. Both the scales consisted of four items based on Malecki and Demary (2002). Examples of items: "I feel that my teachers care about me", "I feel that my teachers treat me in a friendly manner" (emotional support), and "The teachers explain what I don't understand", "My teachers continue to explain until I understand" (academic support). However, a factor analysis showed a single factor structure. Based on this, we decided to use one scale for teacher support in upper secondary school grade 2 based on all eight statements. Cronbach's alpha for the scale was 0.93 for both girls and boys.

\subsubsection{Coping beliefs}

In this study, we use the concept of coping competence as an indicator of coping beliefs in upper secondary school grade 3. Coping competence is defined as "(...) the capacity to effectively cope with failure and negative life events as indicated by a reduced likelihood of helplessness reactions and fast recovery from any occurring 
helplessness symptoms" (Schroder \& Ollis, 2013, p. 288). Coping beliefs was measured with five items from The Coping Competence Questionnaire (Schroder \& Ollis, 2013). This instrument had originally 12 items, and we used the 5 items with the highest loadings from the factor analysis. All the statements are formulated negatively and were turned before we made the scale. Examples of statements: "When I do not succeed right away, I think I will never get it", "When I perform poorly at school, I begin to doubt my abilities". Cronbach's alpha for the scale was 0.88/0.87 for girls/boys, respectively.

\subsubsection{School stress}

School stress in upper secondary school grade 3 was measured using three items based on a scale developed for the international survey, Health Behavior in SchoolAged Children (Samdal et al., 2016), organized and administrated by the World Health Organization. Examples of statements: "I feel exhausted because of schoolwork", "I'm stressed by schoolwork". Cronbach's alpha for the scale was good for both girls (0.88) and boys (0.85).

\subsection{Data analysis}

Initially, an exploratory factor analysis was conducted on five sum scales (school stress, performance-oriented goal structure, peer support, teacher support, and coping beliefs), with a total of 24 statements (2.2 Instruments for details).

The Kaiser-Meyer-Olkin value was 0.90 , exceeding the recommended value of 0.60 (Kaiser, 1970; 1974) and Bartlett`s Test of Sphericity (Bartlett, 1954) reached statistical significance, supporting the factorability of the correlation matrix. Principal component analysis revealed the presence of five components with eigenvalues exceeding 1. The five-component solution explained a total of $69 \%$ of the variance. To aid the interpretation of these three components, oblimin rotation was performed. The rotated solution revealed the presence of a simple structure (Thurstone, 1947) with all five components showing strong loadings and all variables loading substantially on only one component.

The hypothesized model of the connections between the variables presented in Fig. 1 were tested statistically to explore to what degree it was coherent with the observed data. Structural equation modelling (SEM) in the AMOS 26 program was used to analyse the model with latent (unobserved) variables. None of the error terms were allowed to correlate. The coherence between observed data and the hypothesized model is reported as the goodness of fit statistics. The goodness of fit indicators used to assess the model are the Non-Normed Fit Index (NNFI, also known as TLI), the Comparative Fit Index (CFI), and the Root Means Square Error of Approximation (RMSEA), the study also includes chi square. RMSEA $\leq 0.07$, IFI $\geq 0.90 \mathrm{TLI} \geq 0.90, \mathrm{CFI} \geq 0.90$ are considered as indicators of acceptable fit (Byrne, 2001; Hu \& Bentler, 1999). This indicates a plausibility of the associations between the constructs. The model was tested with the whole sample, and then separate 


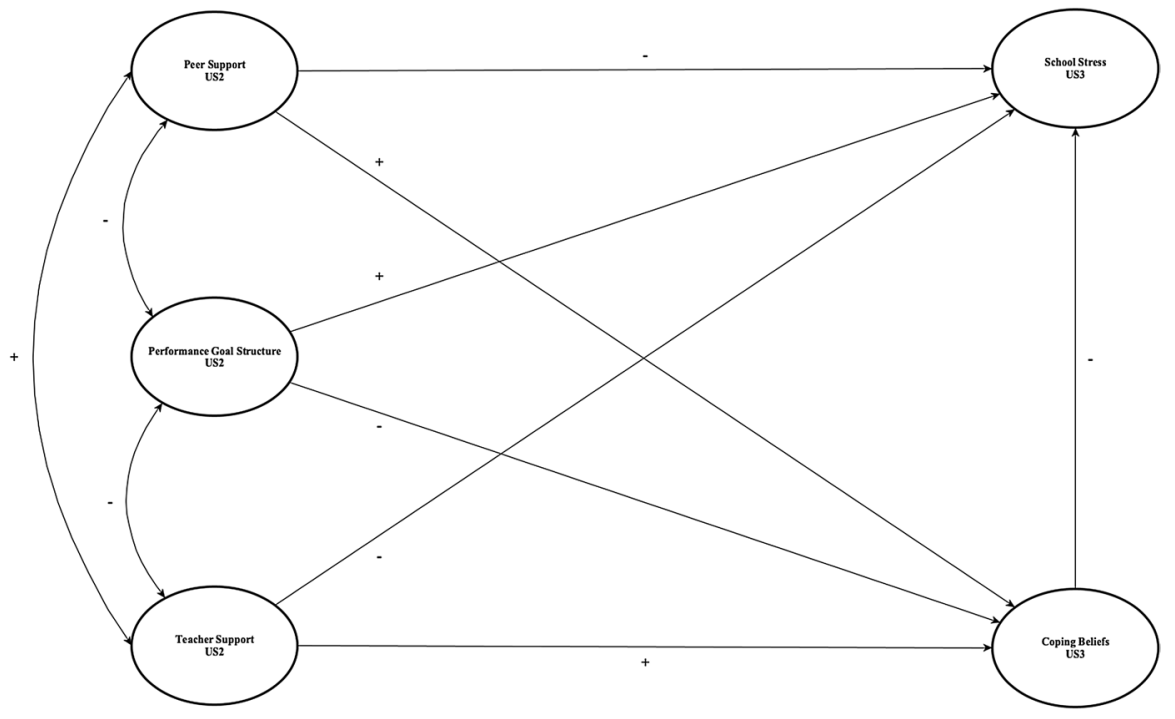

Fig. 1 Theoretical path model

analyses were performed for girls and boys, as research indicates gender differences in the importance of the hypothesized relation between constructs.

\section{Results}

\subsection{Zero order correlations}

Zero order correlations between the study variables as well as $\mathrm{N}$, statistical means, standard deviations and Cohen`s D for girls and boys are shown in Table 1.

Table 1 shows that all correlations between school stress and the other variables were statistically significant for both girls and boys, with the exception of the correlations between performance-oriented goal structure and school stress that was not significant for the boys $(p>0.05)$. The correlations between school stress and performance-oriented goal structure were positive for the girls $(0.21)$. This indicates that the higher the girls perceive a performance-oriented goal structure, the higher they perceive school stress. The correlations between school stress and peer support $(-0.17 / .-12)$, teacher support $(-0.24 /-0.20)$, and coping beliefs $(-0.47 /-0.34)$ were negative for girls/boys, respectively. This indicates that the higher levels of social support and coping beliefs the students experience, the lower levels of school stress they report.

In addition, the mean of school stress was significantly higher for girls (4.31) compared with boys (3.58). An opposite pattern is shown for coping beliefs (4.01/4.60), as the boys have a statistically significant higher mean. Considering effect size, Cohen (1988) claims that an effect of 0.2 is small, 0.5 is medium, and 0.8 is high. The Cohen's D measure thus indicates that the difference in effect size 


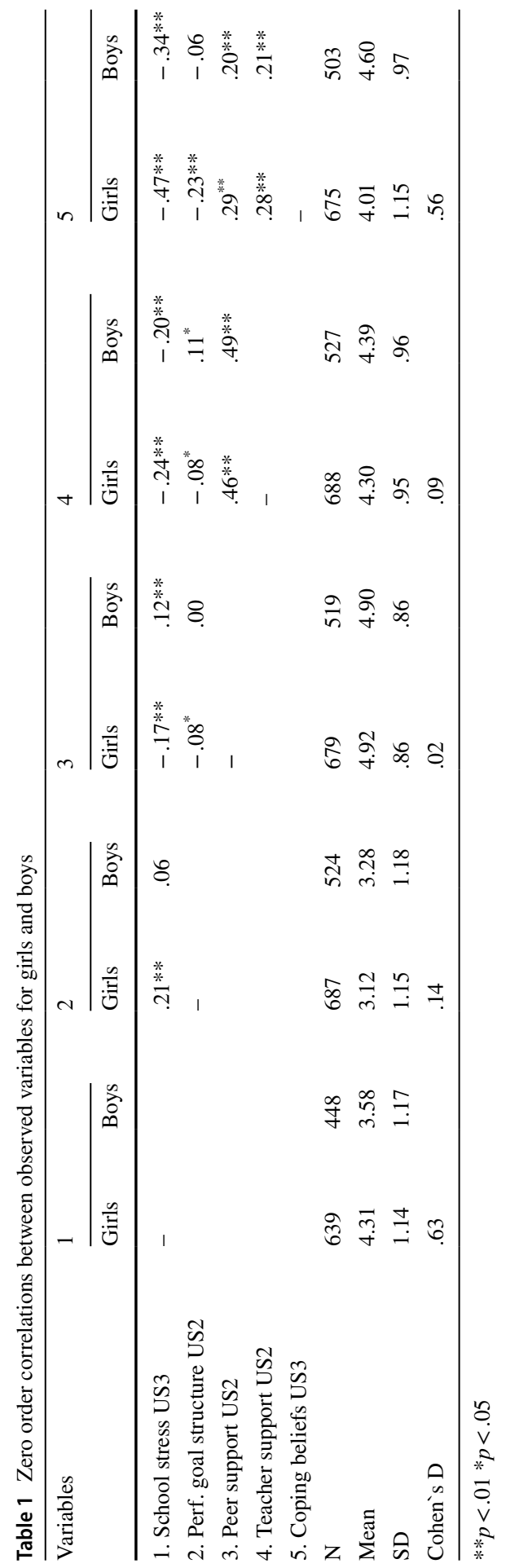


is above medium for both school stress (0.63) and coping beliefs (0.56). The effect size for performance-oriented goal structure (0.14), peer support (0.02), and teacher support (0.09) was under Cohen's limit for concluding a small effect. However, it is somewhat surprising that the boys perceive higher levels of a performance-oriented goal structure, hence they perceive a more competitive environment, but the mean difference from the girls is low and not significant. In all, these findings support H1.

\subsection{SEM analysis}

The relations between the variables were further analysed by means of SEM analysis for latent variables. The model had a satisfactory fit to data: $\mathrm{CFI}=0.960 / 0.964$, $\mathrm{TLI}=0.951 / 0.955, \quad$ RMSEA $=0.047 / 0.043, \quad$ chi $\quad$ square $=604.857 / 475.187$, $\mathrm{df}=242 / 242, p=0.000 / 0.000$, for girls/boys respectively. Figure 2 shows the SEM between performance-oriented goal structure, peer support, teacher support, coping beliefs and school stress. Table 2 presents the significant direct, indirect and total effects in the Structural Equation Model divided by gender.

Figure 2 indicates that the correlation between a perceived classroom performance-oriented goal structure and social support from peers and teachers is not significant, with the exceptions of the correlation between teacher support and a performance-oriented goal structure for boys $(0.14)$. This is somewhat surprising in light of our theoretical path model based on earlier research. However, in line with expected findings, the correlations between peer and teacher support are statistically significant for both girls and boys (0.50/0.57).

A perceived classroom performance-oriented goal structure seems to predict coping beliefs negatively for the girls $(\beta=-0.20)$, but not for the boys. In addition, a performance-orientation seems to positively predict school stress for girls both directly $(\beta=0.10)$ and indirectly through coping beliefs $(0.10)$. However, in contrast to expected findings, we found that the associations between a perceived performance-oriented

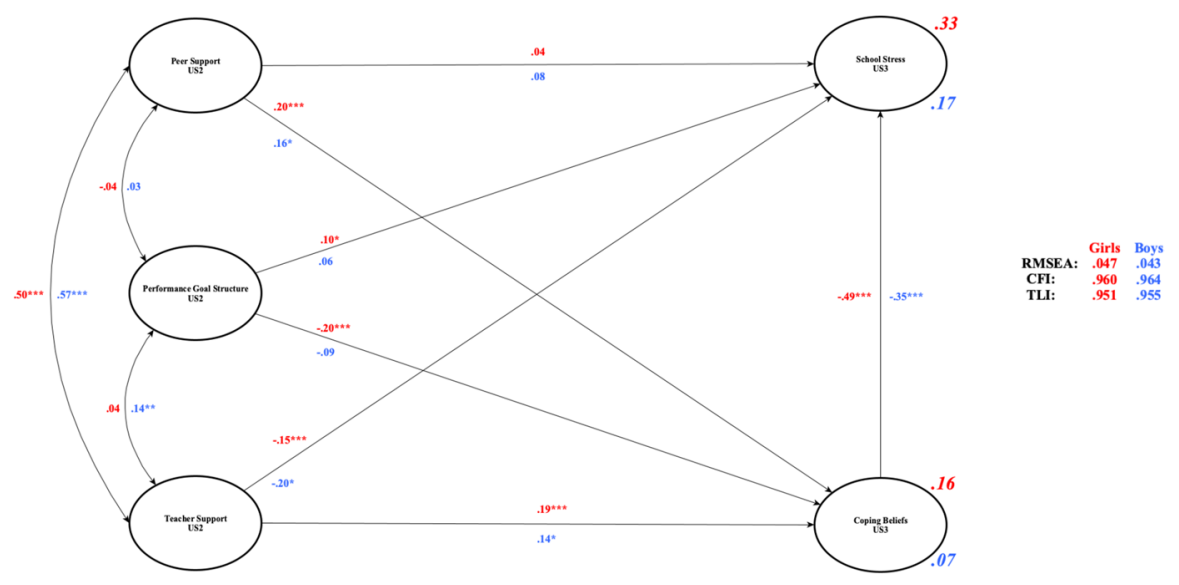

Fig. 2 Structural Equation Model between performance goal structure, peer support, teacher support, coping beliefs and school stress, divided by gender (girls/boys) 
Table 2 Significant direct, indirect and total effects in the structural equation model for girls and boys

\begin{tabular}{|c|c|c|c|c|c|c|}
\hline \multirow[t]{3}{*}{ Variables } & \multicolumn{6}{|c|}{ Effects } \\
\hline & \multicolumn{2}{|c|}{ Direct } & \multicolumn{2}{|c|}{ Indirect } & \multicolumn{2}{|l|}{ Total } \\
\hline & Girls & Boys & Girls & Boys & Girls & Boys \\
\hline \multicolumn{7}{|c|}{ Performance goal structure (USII) } \\
\hline Coping beliefs (USIII) & -.20 & ns & - & - & -.20 & ns \\
\hline School stress (USIII) & .10 & ns & .10 & ns & .20 & ns \\
\hline \multicolumn{7}{|l|}{ Peer support (USI) } \\
\hline Coping beliefs (USIII) & .20 & .16 & - & - & .20 & .16 \\
\hline School stress (USIII) & ns & ns & -.10 & -.06 & -.10 & -.06 \\
\hline \multicolumn{7}{|l|}{ Teacher support (USII) } \\
\hline Coping beliefs (USIII) & .19 & .14 & - & - & .19 & .14 \\
\hline School stress (USIII) & -.15 & -.20 & -.09 & -.05 & -.24 & -.25 \\
\hline \multicolumn{7}{|l|}{ Coping beliefs (USIII) } \\
\hline School stress (USIII) & -.49 & -.35 & - & - & -.49 & -.35 \\
\hline
\end{tabular}

goal structure and neither coping beliefs nor school stress were statistically significant $(p>0.05)$ for the boys. This is a surprising finding as it indicates that the perceptions of a performance-orientation in the classroom does not impact the boys' coping beliefs or experiences of school stress. These findings support $\mathrm{H} 2$ for the girls, but $\mathrm{H} 2$ has to be discarded for the boys.

Peer support seems to positively predict coping beliefs for both girls $(\beta=0.20)$ and boys $(\beta=0.16)$. However, we also find it surprising that peer support does not have a significant direct association with school stress, even though it has a significant negative indirect effect through coping beliefs for both girls $(\beta=-0.10)$ and boys $(\beta=-0.06)$. These findings support $\mathrm{H} 3$ with regard to the relationship between peer support and coping beliefs, but $\mathrm{H} 3$ on the negative association between peer support and school stress has to be discarded for both girls and boys.

Teacher support positively predicts coping beliefs $(\beta=0.19 / 0.14)$ and negatively predicts school stress $(\beta=-0.15 /-0.20)$ for both girls and boys, respectively. In addition, there are indirect negative effects through coping beliefs for both girls $(\beta=-0.09)$ and boys $(\beta=-0.05)$ These findings are in support of $\mathrm{H} 4$.

Coping beliefs negatively predict school stress for both girls $(\beta=-0.49)$ and boys $(\beta=-0.35)$. These findings support H5. In total, the model explains $16 \%$ and $7 \%$ of the variance of perceptions of coping beliefs, and 33\% and 17\% of the variance of the perceptions of school stress, for girls and boys respectively. In all, this indicates that the model fits the girls' development of coping beliefs and experiences of school stress better than it does for the boys. 


\section{Discussion}

The primary goal of this study was to further explore the prevalence of school stress and a proposed pathway between the students' perceptions of a performance-oriented goal structure, social support, coping beliefs and experiences of school stress during Norwegian student's last two years of Upper Secondary School. We adopted Lazarus and Folkman's (1984) transactional model of stress and coping as a theoretical framework, based on an understanding that in addition to the objective demands and expectations over time, the subjective experience is a key concept when we explore the development of stress. It is not solely the pressure from stressors, but also how students appraise the situation, and their available personal and social resources, that determine whether they experience stress (Lazarus, 1966; Lazarus \& Folkman, 1984). The following research question guided the study: "Are upper secondary school students' perceptions of coping beliefs and school stress related to gender, the performance-oriented goal structure in the classroom and their perceptions of social support from teachers and peers?".

The first finding is that coping beliefs are significantly lower and school stress is significantly higher among girls compared with boys. This finding supports our hypothesis based on previous research (Dalen, 2014; Klinger et al., 2015). For the remaining three variables, the effect size was not statistically significant, indicating that both genders perceived their social support from peers and teachers, and the performance-oriented goal structure to the same degree.

The second finding is that the proposed pathway between the students' perceptions of a performance-oriented goal structure, social support, coping beliefs and experiences of school stress during their last two years of Upper Secondary School predicts girls' development of school stress to a higher degree than it does for boys, $33 \%$ and $17 \%$, respectively. Parts of this can be explained by the fact that performance-oriented goal structure neither predicts coping beliefs nor experiences of school stress for boys, while both are statistically significant for girls. The effect of social support on coping beliefs and school stress is more similar between the genders. However, it is surprising that peer support does not predict experiences of school stress directly. Rather it seems that the effect of support from peers is indirect through coping beliefs. In support of earlier research and in line with our proposed pathway and earlier research, teacher support predicts coping beliefs positively and school stress negatively. In addition, as expected, coping beliefs predict experiences of school stress negatively for both genders.

In all, these finding are interesting in light of Lazarus and Folkman's (1984) transactional model and earlier research. It does not seem to be the extent of performance pressure or social support that leads to the girls having more extensive experiences of school stress, instead it suggests that girls are more vulnerable towards school stressors, particularly the performance pressure in the goal structure at school, compared with boys. The difference between the two genders' mean level of perceptions of a performance-oriented goal structure is not statistically significant, and the mean level between both coping beliefs and experiences 
of school stress has a relatively high effect size. Based on this, it is plausible to argue that it is not the objective extent of pressure, but the subjective interpretation of the amount of this pressure that leads to high levels of experienced school stress amongst adolescent girls.

One possible explanation is that girls to a greater extent than boys reflect their self-worth in how they succeed at school (Oltenau et al., 2019; Smith \& Kirby, 2009). As external stressors depend on subjective interpretations, characterized by our values, the social roles we hold and past experience, the same amount of actual demands and expectations can be considered unproblematic for some and pose a health risk for others (Avison, 2010; Thoits, 2010). At the same time, the potential for experiencing a situation with extensive pressure as stressful can be related to gender differences in optimistic coping beliefs, and to differences in girls' and boys' coping strategies that were not scrutinized in this study.

\subsection{Limitations and future directions}

This study has some limitations. Future studies should use more extensive longitudinal and experimental designs to test the development of different associations between adolescents' sense of stress, and personal and environmental factors from several microsystems over time. In addition, all data were based on students' selfreports. It seems appropriate and expedient to employ more objective measures of social dynamics (e.g. social network analysis) and triangulate the subjective perceptions in the self-reports by the use of several informants, such as friends, parents, and teachers. Furthermore, this study has only measured individual-level factors. Future studies should include factors at the class-level and school-level through multi-level analysis to investigate how these systemic variables may influence students' perceived school ecology, coping beliefs and school stress. Several studies have revealed that differences in the classroom or school environment exist across classes at school level (e.g. Danielsen et al., 2010; Kashy-Rosenbaum et al., 2018). These possible associations are in need of further scrutiny.

\section{Conclusion}

Although this study has some limitations, the results mainly support previous research. The importance of social support in the school environment, especially from teachers, is supported in this study. In addition, our results indicate some surprising gender differences related to the impact of the goal structure at school that need to be explored in future research. A holistic understanding of school stress should include knowledge of both internal and external stressors and resources. This encompasses knowledge of which external factors in the social environment at school protect and challenge adolescents' experience of stress. In addition, a holistic understanding requires that we also develop knowledge about which personal factors reduce and increase subjective experiences of stress, respectively. In a school context, the school organization and workforce have a responsibility to keep the 
challenges at a level that enables adolescents to cope with them. At the same time, the school has a responsibility to build resistance resources in the individual adolescent in order to reduce the possibility that everyday school life is perceived as overwhelming. In all, our findings call for further scrutiny of the quality, characteristics and dynamics of external factors such as the classroom climate, and internal factors such as coping beliefs, when it comes to understanding adolescents' experience of school stress.

Funding Open access funding provided by NTNU Norwegian University of Science and Technology (incl St. Olavs Hospital - Trondheim University Hospital). None.

\section{Declarations}

Conflict of interest The authors declare no conflict of interest.

Ethical approval The study was considered and accepted by the Norwegian Centre for Research Data, the 0 Regional Committees for Medical and Health Research Ethics, Norway and the Norwegian Data Protection Authority.

Informed consent Informed consent was obtained from all participants, Additionally, parents were sent an information letter with the option to opt their child out of the study. The study was approved by the Norwegian Data Inspectorate.

Open Access This article is licensed under a Creative Commons Attribution 4.0 International License, which permits use, sharing, adaptation, distribution and reproduction in any medium or format, as long as you give appropriate credit to the original author(s) and the source, provide a link to the Creative Commons licence, and indicate if changes were made. The images or other third party material in this article are included in the article's Creative Commons licence, unless indicated otherwise in a credit line to the material. If material is not included in the article's Creative Commons licence and your intended use is not permitted by statutory regulation or exceeds the permitted use, you will need to obtain permission directly from the copyright holder. To view a copy of this licence, visit http://creativecommons.org/licen ses/by/4.0/.

\section{References}

Aldrige, J. M., \& McChesney, K. (2018). The relationships between school climate and adolescent health and wellbeing: A systematic literature review. International Journal of Educational Research, 88, 121-145.

Ames, C., \& Archer, J. (1988). Achievement goals in the classroom: Students' learning strategies and motivation processes. Journal of Educational Psychology, 80(3), 260-267.

Anderman, E. M., Cupp, P. K., \& Lane, D. (2009). Impulsity and academic cheating. Journal of Experimental Education, 78(1), 135-150.

Arslan, C. (2009). Anger, self-esteem and perceived social support in adolescence. Social Behavior \& Personality: An International Journal, 37(4), 555-564.

Avison, W. R. (2010). Incorporating children`s lives into a life course perspective on stress and mental health. Journal of Health and Social Behavior, 51(4), 361-375.

Bakken, A., Sletten, M. A., \& Eriksen, I. M. (2018) Generasjon prestasjon? Ungdoms opplevelse av press og stress. [Generations performance? Adolescence experience of pressure and stress]. Norwegian Journal of Youth Research, 18(2), 46-76. 
Byrne, B. M. (2001). Structural equation modelling with AMOS, EQS, and LISREL: Comparative Approaches to Testing for the Factorial Validity of a Measuring Instrument. International Journal of Testing, 1(1), 55-86.

Byrne, D. G., Davenport, S. C., \& Mazanov, J. (2007). Profiles of adolescent stress: The development of the adolescent stress questionnaire (ASQ). Journal of Adolescence, 30(3), 393-416.

Bücker, S., Nuraydin, S., Simonsmeier, B. A., Schneider, M., \& Luhman, M. (2018). Subjective wellbeing and academic achievement: A meta-analysis. Journal of Research in Personality, 74, 83-94.

Card, N. A., \& Little, T. D. (2007). Longitudinal modeling of developmental processes. International Journal of Behavioral Development, 31(4), 297-302.

Cheng, S. T., \& Chan, A. (2004). The multidimensional scale of perceived social support: Dimensionality and age and gender differences in adolescents. Personality and Individual Differences, 37, 1359-1369.

Cohen, J., McCabe, E. M., Michelli, N. M., \& Pickeral, T. (2009). School climate: Research, policy, practice and teacher education. Teachers College Record, 111(1), 180-213.

Dalen, J. D. (2014). Gender differences in the relationship between school problems, school class context and psychological distress: Results from the Young-HUNT 3 study. Social Psychiatry and Psychiatric Epidemiology, 49(2), 183-191.

Danielsen, A. G., Samdal, O., Hetland, J., \& Wold, B. (2009). School-related social support and students' perceived life satisfaction. The Journal of Educational Research, 102(4), 303-320.

Danielsen, A. G., Wiium, N., Willhelmsen, B. U., \& Wold, B. (2010). Perceived support provided by teachers and classmates and student's self-reported academic initiative. Journal of School Psychology, 48(3), 247-267.

Davis, H. A. (2006). Exploring the contexts of relationship quality between middle school students and teachers. The Elementary School Journal, 106(3), 193-223.

Downer, J. T., Stuhlman, M., Schweig, J., Martinez, J. F., \& Ruzek, E. (2015). Measuring effective teacher-student interactions from a student perspective: A multi-level analysis. Journal of Early Adolescence, 35(5-6), 722-758.

Dull, R. B., Schleifer, L. L., \& McMillan, J. J. (2015). Achievement goal theory: The relationship of accounting students' goal orientations with self-efficacy, anxiety, and achievement. Accounting Education, 24(2), 152-174.

Eisenberg, D., Hunt, J., Speer, N., \& Zivin, K. (2011). Mental health service utilization among college students in the United States. Journal of Nervous and Mental Disease, 199(5), 301-308.

Eriksen, I. M., Sletten, M. A., Bakken, A., \& Von Soes, T. (2017). Stress og press blant ungdom. Erfaringer, årsaker og utbredelse av psykiske helseplager. [Stress and press among youth. Experiences, causes and prevalence of mental health problems]. (Report nr. 6/17.). Oslo: NOVA.

Fortin, L., Marcotte, D., Diallo, T., Potvin, P., \& Royer, E. (2013). A multidimensional model of school dropout from an 8-year longitudinal study in a general high school population. European Journal of Psychology of Education, 28(2), 563-583.

Giota, J., \& Gustafsson, J. E. (2016). Perceived demands of schooling, stress and mental health: Changes from grade 6 to grade 9 as a function of gender and cognitive ability. Stress and Health, 33(3), 253-266.

Goldstein, S. E., Boxer, P., \& Rudolph, E. (2015). Middle school transition stress: Links with academic performance, motivation, and school experiences. Contemporary School Psychology, 19, 21-29.

Groth, N., Schnyder, N., Kaess, M., Markovic, A., Rietschel, L., Moser, S., Michel, C., Schultze-Lutter, F., \& Schmidt, S. J. (2019). Coping as a mediator between locus of control, competence beliefs, and mental health: A systematic review and structural equation modelling meta-analysis. Behaviour Research and Therapy., 1(121), 103442.

Hankin, B. L., Mermelstein, R., \& Roesch, L. (2007). Sex differences in adolescent depression: Stress exposure and reactivity models. Child Development, 78(1), 279-295.

Henry, D. B., Farrell, A. D., Schoeny, M. E., Tolan, P. H., \& Dymnicki, A. B. (2011). Influence of schoollevel variables on aggression and associated attitudes of middle school students. Journal of School Psychology, 49(5), 481-503.

Huang, C. (2016). Achievement goals and self-efficacy: A meta-analysis. Educational Research Review, $19,119-138$.

Hulleman, C. S., Schrager, S. M., Bodmann, S. M., \& Harackiewicz, J. M. (2010). A meta-analytic review of achievement goal measures: Different labels for the same constructs or different constructs with similar labels? Psychological Bulletin, 136(3), 422-449. 
Högberg, B., Strandh, M., \& Hagquist, C. (2020). Gender and secular trends in adolescent mental health over 24 years-The role of school-related stress. Social Science and Medicine, 250, 11890.

Jennings, P. A., \& Greenberg, M. T. (2009). The prosocial classroom: Teacher social and emotional competence in relation to student and classroom outcomes. Review of Educational Research, 79(1), 491-525.

Johnson, J., Panagioti, M., Bass, J., Ramsey, L., \& Harrison, R. (2017). Resilience to emotional distress in response to failure, error or mistakes: A systematic review. Clinical Psychology Review, 52, 19-42.

Kashy-Rosenbaum, G., Kaplan, O., \& Israel-Cohen, Y. (2018). Predicting academic achievement by class-level emotions and perceived homeroom teachers' emtional support. Psychology in the Schools, 55, 770-782.

Klinger, D. A., Freeman, J. G., Bliz, L., Liiv, K., Ramelow, D., Sebok, S. S., Samdal, O., Dür, W., \& Rasmussen, M. (2015). Cross-national trends in perceived school pressure by gender and age from 1994 to 2010. European Journal of Public Health, 25(2), 51-56.

Kong, F., Zhao, J., \& You, X. (2013). Self-esteem as mediator and moderator of the relationship between social support and subjective well-being among Chinese university students. Social Indicators Research, 112(1), 151-161.

Lazarus, R. S. (1966). Psychological stress and the coping process. McGraw-Hill.

Lazarus, R. S., \& Folkman, S. (1984). Stress, appraisal, and coping. Springer Publishing Company Inc.

Lei, H., Cui, Y., \& Chiu, M. M. (2018). The relationship between teacher support and students' academic emotions: A meta-analysis. Frontiers in Psychology, 8(2288), 1-12.

Lerang, M. S., Ertesvåg, S. K., \& Havik, T. (2019). Perceived classroom interaction, goal orientation and their association with social and academic learning outcomes. Scandinavian Journal of Educational Research, 63(6), 913-934.

Lillejord, S., Børte, K., Ruud, E., \& Morgan, K. (2017). Stress i skolen - en systematisk kunnskapsoversikt. [Stress in School - a systematic review]. Oslo: The Research Council of Norway.

Long, E., Zucca, C., \& Sweeting, H. (2020). School climate, peer relationships, and adolescent mental health: A social ecological perspective. Youth and Society. https://doi.org/10.1177/0044118X20 970232

Löfstedt, P., Eriksson, C., Potrebny, T., Välimaa, R., Thorsteinsson, E. B., Due, P., Damsgaard, M. T., Suominen, S., Rasmussen, M., \& Torsheim, T. (2019). Trends in perceived school stress among adolescents in five Nordic countries 2002-2014. Nordic Welfare Research, 4(2), 101-112.

Löfstedt, P., García-Moya, I., Corell, M., Paniagua, C., Samdal, O., Välimaa, R., Lyyra, N., Currie, D., \& Rasmussen, M. (2020). School satisfaction and school pressure in the WHO European Region and North America: An analysis of time trends (2002-2018) and patters of co-occurrence in 32 countries. Journal of Adolescent Health, 66(6), 559-569.

Malecki, C. K., \& Demary, M. C. (2002). Measuring perceived social support: Development of the Child and Adolescent Social Support Scale (CASS). Psychology in the Schools, 39(1), 1-18.

McQueen, R. A., \& Knussen, C. (2006). Introduction to Research Methods and Statistics in Psychology. Harlow, ND: Pearson Education.

Mehta, M. H., Grover, R. L., DiDonato, T. E., \& Kirkhart, M. W. (2018). Examining the positive cognitive triad: A link between resilience and well-being. Psychological Reports, 1, 1-13.

Midgley, C., Maehr, M. L., Hruda, L. Z., Anderman, E., Anderman, L., Freeman, K. E., \& Urdan, T. (2000). Manual for the patterns of adaptive learning scales. Universtity of Michigan.

Montgomery, C. (2012). A literature review and analysis of stress and coping. Journal of Ottawa University, 5(11), 78-95.

Morris, M. C., Ciesla, J. A., \& Garber, J. (2010). A prospective study of stress autonomy versus stress sensitization in adolescents at varied risk for depression. Journal of Abnormal Psychology, 119(2), $341-354$.

Moses, J. O., \& Villodas, M. T. (2017). The potential protective role of peer relationships on school engagement in at-risk adolescents. Journal of Youth and Adolescence, 46(11), 2255-2272.

Nicholls, J. G. (1984). Achievement motivation: Conceptions of ability, subjective experience, task choice, and performance. Psychology Review, 91(3), 328-346.

OECD (2017). PISA 2015 Results (Volume III). Paris, France.

Oltenau, L., Golani, S., Eitam, B., \& Kron, A. (2019). The effect of relevance appraisal on the emotional response. Emotion, 19(4), 715-725.

Pargas, R. C., Brennan, P. A., Hammen, C., \& Le Brocque, R. (2010). Resilience to maternal depression in young adulthood. Developmental Psychology, 46(4), 805-814. 
Pascoe, M. C., Hetrick, S. E., \& Parker, A. G. (2020). The impact of stress on students in secondary school and higher education. International Journal of Adolescence and Youth, 25(1), 104-112.

Patrick, H., Kaplan, A., \& Ryan, A. M. (2011). Positive classroom motivational environments: Convergence between mastery goal structure and classroom social climate. Journal of Educational Psychology, 103(2), 367-382.

Pianta, R. C., \& Hamre, B. K. (2009). Conceptualization, measurement, and improvement of classroom processes: Standardized observation can leverage capacity. Educational Researcher, 38, 109-119.

Pianta, R. C., Hamre, B. K., \& Mintz, S. L. (2010). Classroom assessment scoring system manualUpper elementary. University of Virginia.

Polychroni, F., Hatzichristou, C., \& Sideris, G. (2012). The role of goal orientations and goal structures in explaining classroom social and affective characteristics. Learning and Individual Differences, 22(2), 207-217.

Poots, A., \& Cassidy, T. (2020). Academic expectation, self-compassion, psychological capital, social support and student wellbeing. International Journal of Educational Research, 99, 1.

Raboteg-Saric, Z., \& Sakic, M. (2014). Relations of parenting styles and friendship quality to self-esteem, life satisfaction and happiness in adolecents. Applied Research in Quality of Life, 9(3), 749-765.

Randall, E. T., Shapiro, J. B., Smith, K. R., Jervis, K. N., \& Logan, D. E. (2019). Under pressure to perform: impact of academic goal orientation, school motivational climate, and school engagement on pain and somatic symptoms in adolescents. The Clinical Journal of Pain, 35(12), 967-974.

Ringdal, R., Espnes, G. A., Eilertsen, M. E., Bjørnsen, H. N., \& Moksnes, U. K. (2020). Social support, bullying, school-related stress and mental health in adolescence. Nordic Psychology., 72(4), 313-30.

Rolland, R. G. (2012). Synthesizing evidence on classroom goal structures in middle and secondary schools: A meta-analysis and narrative review. Review of Educational Research, 82(4), 396-435.

Rose, A. J., \& Rudolph, K. D. (2006). A review of sex differences in peer relationship processes: Potential trade-offs for the emotional and behavioral development of girls and boys. Psychological Bulletin, 132, 98-131.

Rudasill, K. M., Reio, T. G., Stipanovic, N., \& Taylor, J. E. (2010). A longitudinal study of studentteacher relationship quality, difficult temperament, and risky behvior from childhood to early adolescence. Journal of School Psychology, 48(5), 389-412.

Rueger, S. Y., Malecki, C. K., \& Demaray, M. K. (2008). Gender differences in the relationship between perceived social support and student adjustment during early adolescence. School Psychology Quarterly, 23, 496-514.

Salmela-Aro, K. (2017). Dark and bright sides of thriving-school burnout and engagement in the Finnish context. European Journal of Developmental Psychology, 14(3), 337-349.

Samdal, O., Mathisen, F. K. S., Torsheim, T., Diseth, A. R., Fismen, A.-S., Larsen, T., \& Årdal, E. (2016). Helse og trivsel blant barn og unge. Resultater fra den landsrepresentative spфrreunders $\phi k e l s e n$ «Helsevaner blant skoleelever. En WHO-unders $\phi$ kelse i flere land». [Health and well-being among children and young people. Results from the nationally representative survey "Health habits among school students. A WHO-survey in several countries"]. Bergen: HEMIL-senteret.

Sawatzky, R. G., Ratner, P. A., Richardson, C. G., Washburn, C., Sudmant, W., \& Mirwaldt, P. (2012). Stress and depression in students: The mediating role of stress management self-efficacy. Nursing Research, 61(1), 13-21.

Schraml, K., Perski, A., Grossi, G., \& Makower, I. (2012). Chronic stress and its consequences on subsequent academic achievement among adolescents. Journal of Educational and Developmental Psychology, 2(1), 69-79.

Schroder, K. E. E., \& Ollis, C. L. (2013). The coping competence questionaire: A measure of resilience to helplessness and depression. Motivation and Emotion, 37(2), 286-302.

Selye, H. (1956). The stress of life. McGraw-Hill Book Company.

Shek, D. T. L., \& Catalina, S. M. (2016). Longitudinal research design in adolescent developmental research. International Journal on Disability and Human Development, 15(4), 349-358.

Silk, J. S., Vanderbilt-Adriance, E., Shaw, D. S., Forbes, E. E., Whalen, D. J., Ryan, D. R., \& Dahl, R. E. (2007). Resilience among children and adolescence at risk for depression: Mediation and moderation across social and neurobiological contexts. Development and Psychopathology, 19(3), 841-865.

Skaalvik, E. M., \& Skaalvik, S. (2013). School goal structure: Associations wiht students' perceptions of their teachers as emotionally supportive, academic self-concept, intrinsic motivation, effort, and help seeking behavior. International Journal of Educational Research, 61, 5-14.

Smith, C., \& Kirby, L. D. (2009). Putting appraisal in context: Toward a relational model of appraisal and emotion. Cognition and Emotion, 23(7), 1352-1372. 
Sowislo, J. F., \& Orth, U. (2013). Does low self-esteem predict depression and anxiety? A meta-analysis of longitudinal studies. Psychological Bulletin, 139(1), 213-240.

Statistics Norway (2018). Gjennomstrømning i videregående opplæring, 2012-2017. [Throughput in upper secondary education, 2012-2017].

Suldo, S. M., Friedrich, A. A., White, T., Farmer, J., Minch, D., \& Michalowski, J. (2009). Teacher support and adolescents' subjective well-being: A mixied-methods investigation. School Psychology Review, 38(1), 67-85.

Thapa, A., Cohen, J., Guffey, S., \& Higgins-D’Alessandro, A. (2013). A review of school climate research. Review of Educational Research, 83(3), 357-85.

Thapa, A., Cohen, J., Higgins-D`Alessandro, A., Guffey, S. (2012). School Climate Reserach Summary: August 2012. School Climate Brief, Number 3. National School Climate Center.

Thapar, A., Collishaw, S., Pine, D. S., \& Thapar, A. K. (2012). Depression in adolescence. Lancet, 379(9820), 1056-1067.

Thoits, P. A. (2010). Stress and health: Major findings and policy implications. Journal of Health and Social Behavior, 51(41), 53.

Tian, L., Tian, Q., \& Huebner, E. S. (2016). School-related social support and adolescents' school-related subjective well-being: The mediating role of basic psychological needs satisfaction at school. Social Indicators Research, 128(1), 105-129.

Tian, L., Yu, T., \& Huebner, E. S. (2017). Achievement goal orientations and adolescents` subjective well-being in school: The mediating roles of academic social comparison directions. Frontiers in Psychology, 8(37), 1-11.

Varghese, R., Norman, T. S., \& Thavaraj, S. (2015). Perceived stress and self efficacy among college students: A global review. International Journal of Human Resource Management and Research, 5(3), 15-24.

Vogel, S., \& Schwabe, L. (2016). Learning and memory under stress: Implications for the classroom. npj Science of Learning, 1(1), 1-10.

Walburg, V. (2014). Burnout among high school students: A literature review. Children and Youth Services Review, 42, 28-33.

Wang, M. T., \& Degol, J. L. (2016). School climate: A review of the construct, measurement, and impact on student outcomes. Educational Psychology Review, 28, 315-352.

Wang, M. T., Degol, J. L., Ameniya, J., Parr, A., \& Guo, J. (2020). Classroom climate and children's academic and psychological wellbeing: A systematic review and meta-analysis. Developmental Review, 57,100912 .

Wentzel, K. R., Battle, A., Russell, S. L., \& Looney, L. B. (2010). Social supports from teachers and peers as predictors of academic and social motivation. Contemporary Educational Psychology, 35(3), 193-202.

Wolters, C. A. (2004). Advancing acheivement goal theory. Using goal structures and goal orientations to predict students' motivation, cognition, and acheivement. Journal of Educational Psychology, 96(2), 236-250.

Yeoh, S. H., Tam, C. L., Wong, C. P., \& Bonn, G. (2017). Examining depressive symptoms and their predictors in Malaysia: Stress, locus of control, and occupation. Frontiers in Psychology, 8(8), 1-10.

Zullig, K. J., Huebner, E. S., \& Patton, J. M. (2011). Relationships among school climate domains and school satisfaction. Psychology in the Schools, 48(2), 133-145.

Publisher's Note Springer Nature remains neutral with regard to jurisdictional claims in published maps and institutional affiliations.

Jan Arvid Haugan is an Associate Professor at the Norwegian University of Science and Technology. His research interests are the interaction between the mutually influential individual/contextual factors within and across different microsystems in adolescence life-ecology, especially the microsystems related to sports and education.

Per Frostad is a professor at the Norwegian University of Science and Technology. His research interests are social inclusion, mental health and wellbeing in upper secondary schools. 
Per-Egil Mjaavatn is a Associate Professor at the Norwegian University of Science and Technology. His research interests are everyday life and wellbeing among children and youth. Students opinions about their physical and mental health, social relations and their experiences in the education system. 